\title{
Enhancing the Mechanical Properties of Metal Matrix Composites by Reinforcing Aluminum 6063 with Silicon Carbide and Mica
}

\author{
Shabana, R.V.Nikhil Santosh
}

\begin{abstract}
Metal matrix composites (MMC) Are metals covered with diverse metals, stoneware or commonplace fragments. This essentially performed to beautify the homes of base metallic like high-quality, electricity, conductivity, and so on., Aluminum and its amalgams have pulled in most concept as a base steel in metallic lattice composites. Al MMC are typically applied in carrier, flying and severa area. This paper attempts to look the improvement of mechanical residences with the useful resource of the aggregate of Aluminum 6063 (Al6063) fortified with Silicon Carbide (SiC) and Mica composites made through combo tossing technique. The precedents are set up with aluminum changing with Silicon carbide via the use of weight percent of (12\%, 13\% and 14\%) and mica (2\%). Tests had been guided on these composites to evaluate how the flexibility, microhardness, flexural high-quality, compressive fine and microstructures of the materials were affected.
\end{abstract}

Keywords:Aluminum Metal Matrix Composites (AMMC), Silicon Carbide, Mica, Stir Casting Technique.

\section{INTRODUCTION}

Aluminum is remarkable for its low thickness and its capacity to withstand utilization. To benefit houses like extraordinary Tensile power, Compressive power, Microhardness, Flexural control diverse aluminum composites are being dealt with. Composite substances are those which might be shaped by using method for the blend of or more substances to verify houses which can be better than the choose metallic. Aluminum composites had been used these days in avionics and vehicle organizations. [1]. AMMCs can be produced by technique for liquid nation planning (blend tossing, infiltration, press tossing and various others.), semisolid dealing with and powder metallurgical course. usually non-metallic and terminated particles like silicon carbide ( $\mathrm{SiC})$, alumina (Al2O3), boron carbide (B4C), graphite, and so on. Are used as fortresses in AMMCs.while hundreds are cultivated remotely to the composites, metallic structure transmits hundreds to fortresses after which hundreds are passed on by dispersed strongholds fortified with the grid. solid interface bond among fortresses and cross section is required to get superfluous force of composites. Interface bond is molded with the accommodating resource of response or normal breaking down in some unspecified time later on of tossing. in this

Revised Manuscript Received on April 12, 2019.

Dr. Shabana,Assistant professor, Department of Industrial engineering, GIT, GITAM University, Visakhapatnam, AP. (Email: shabana.shabana@gitam.edu)

R.V.NikhilSantosh,B.Tech 4/4., Department of Mechanical Engineering, GIT, GITAM University, Visakhapatnam, A.P (Email: nikhilr117@gmail.com) manner, fitting wetting of the strongholds is crucial in some unspecified time later on of tossing [2]. it is been found that using AMCs in engine activities can decrease the general weight, fuel use and pollution in the motors and flying machines [3]. AMCs strengthened with both silicon carbide (three.18 g/cm3) or alumina $(3.9 \mathrm{~g} / \mathrm{cm} 3)$ debris are drawing in materials for such applications [4].the ones strongholds are denser than the ones of aluminum amalgams $(2.7 \mathrm{~g} / \mathrm{cm} 3)$ and could shoot the stack of the composites depending at the help's substance [5]. investigate on substances in the midst of the prop up different a whole deal has made two or three better materials with living plans transcendent than standard substances, this sort of being Hybrid metallic Matrix Composites (HMCs) which have over the top definite power, toughness, influence quality and coffee affectability to temperature modifications [6].The properties of the cross breed fortresses (basic and discretionary) can be blended to acquire streamlining of texture houses. likewise, using blend tossing procedure for production of AMCs diminishes the esteem the composites, as it's miles sufficiently evaluated, simple to perform and really beneficial framework [7].

inside the present show-stopper try has been made to examine the effect of $\mathrm{Mica} / \mathrm{SiC}$ extension on the mechanical direct of 6063 Aluminum composite. Mica is a sort of phyllosilicate, showing up - dimensional sheet or layer shape. it is truely happening stone that speedily applies to a hard and snappy of minerals containing silica in its most bewildering structure. Mica has the houses including outrageous strength, radical pliable electricity,and flexible and correspondingly everything considered with being versatile and it has famous weight quality. Silicon carbide ( $\mathrm{SiC}$ ), alsoknown as carborundum is a semiconductor containing silicon and graphite. $\mathrm{SiC}$ stronghold will fabricate the flexible power, hardness, thickness and put on impediment of $\mathrm{Al}$ and its composites. The particulate MMC are essentially used for tribological packages because of incredible put on restriction for the term of sliding further to its capacity to withstand over the top weight and their ability to keep up heavier masses. on this examination mix giving is used a job as it's miles routinely going on as an unequivocally promising method, before long may be cleaned monetarily. Its gifts lie in its ease, flexibility and congruity to colossal sum creation and it lets in a standard steel taking care of approach to be used, and along these

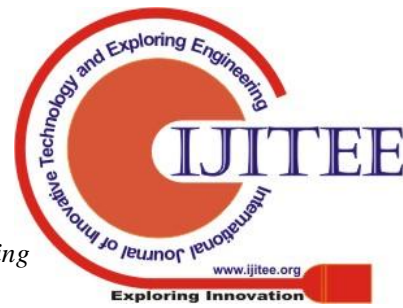




\section{Carbide And Mica}

lines restricts the last charge of the thing. In exquisite, the solidifying association of metallic system composites includes making a relax of the picked cross section material found with the guide of method for the introduction of a stronghold surface into the break down. To acquire an appropriate dispersing the mix tossing procedure is used. The mechanical houses - tractable essentialness, compressive quality, flexural power and little scale hardness of Aluminium6063 securing 2\%Mica as enduring andaddingSiC by using the usage of different its $\mathrm{Wt} . \%$ through $12 \%$, thirteen $\%, 14 \%$ in this gem.

\section{Composing SURVEY:}

T. Rajmohan has surveyed the mechanical and set on spots of crossbreed aluminum grid composites. Mica and $\mathrm{SiC}$ terminated particles have been consolidated into Al 356 amalgam by strategy for technique for blend tossing course. Microstructures of the models had been mulled over the usage of sifting electron amplifying instrument (SEM). The substance creation twisted up explored by methods for imperativeness dispersive X-pillar (EDX) locator. Mica strengthened composites reveals tons less set on disaster and better thickness in examination with the dirt sustained compositesThe results of his break down suggest that the higher impact and hardness were done with $\mathrm{Al} / 10 \mathrm{SiC}-3$ mica composites. The impact in mass segment of mica improves the damage nonappearance of the composites.

Md. Habibur Rahman considered generally the microstructures, mechanical houses and set on properties of as solid silicon carbide ( $\mathrm{SiC})$ upheld aluminum grid composites (AMCs). AMCs of various $\mathrm{SiC}$ content material (zero, five, 10 and 20 wt. \%) had been dealt with the advantage of mix tossing structure. Microstructures, Vickers hardness, pliant power and destroy execution of the arranged composites were analyzed. The test results exhibited that introducing $\mathrm{SiC}$ strongholds in aluminum system extended hardness and flexible power and $20 \mathrm{wt}$ \% SiC braced AMC showed most hardness and flexibility. Microstructuralobservation found gathering and nonhomogeneous spread of $\mathrm{SiC}$ junk inside the $\mathrm{Al}$ lattice. Porosities have been seen in microstructures and improved with creating wt. \% of SiC fortresses in AMCs. Stick onplate put on examine showed thatreinforcing $\mathrm{Al}$ grid with $\mathrm{SiC}$ particles enlivened put on restriction.

Jaswinder Singh inquired about the likelihood and reasonableness of growing low charge radical performancehybrid composites for vehicle and avionics groups. moreover, the assembling characteristics and mechanical direct of HAMCs made through blend tossing course have furthermore beenreviewed. The thickness, hardness, versatile direct and break toughnessof these composites have been both relative or superior to the ceramicreinforced composites. The thickness of HAMCs extended with creating substance of imaginative strongholds, even as solidification of partial fortresses like fly slag, rice husk red hot remains, mica, and so on. Lessens the thickness of composites.in any case, the porosity ranges picked up in those composites have been observed to be inside impeccable cutoff focuses.

Prashant S N found that the hardness of the Al6061-SiC composite will impact with extending proportion of fortress anyway wherein as in Al6061-Graphite composite creating proportion of Graphite has realized lower of hardness. The versatile imperativeness showed a few advancement as the degree segment of stronghold end up being advanced. the damage and tear rate changed into set out to be reduced with widened $\mathrm{SiC}$ content material however as the mischief cost of the Al6061-Graphite composite saw to lessen up to 6 $\mathrm{wt} \%$ anyway starting there it keeps an eye on augmentation.

\section{Exploratory system:}

The aluminum 6063 sums are disintegrated at sevenhundred ${ }^{\circ} \mathrm{C}$ in warmer utilizing setting 600 grams in a pot. exactly when the condensing is executed, it's far mixed with an alluring stirrer with the assistance of sharp edges related with the helping stand. This besides helps as pre-warming contraption. the blend is finished by strategies for taking powder of sustaining materials which are mica and SiC in little packages of aluminum foil in consistence with the dimension of the given mineral, Mica (2\%), and one of a kind compound silicon carbide $(12 \%, 13 \%$ and 14\%) and delicate measure of Magnesium is furthermore brought to structure the holding countless the aluminum, silicon carbide and Mica. The fluid metallic is poured in to a barrel formed shaped shading. This composite is cooled with air as medium. After brief while the solid composite is isolated. the general strong composite is made into precedents required for the pliable, compressive, flexural, little scale hardness and littler scale shape checks. For tractable it hinders with an all out time of eleven. $7 \mathrm{~cm}$ of which $30 \mathrm{~mm}$ in beginning ought to be of $12 \mathrm{~mm}$ width proceeded by method for $57 \mathrm{~mm}$ length with an estimation of $8 \mathrm{~mm}$ and wrapped up with once again $30 \mathrm{~mm}$ period with $12 \mathrm{~mm}$ expansiveness as checked in parent 2. For compressive little sums with length of one. $4 \mathrm{~cm}$ with expansiveness of $1 \mathrm{~cm}$ is made as confirmed in parent three. parent 4 shows the precedent made for the flexural level plate and for the scaled down scale hardness and littler scale essential examine a little piece is taken and cleaned all around finely repeat like a face are made. The phrasing of the precedents is according to the accompanying Aluminum 6063 advanced toward getting to be named as model $\mathrm{I}$ and $\mathrm{Al} 6063+12 \% \mathrm{SiC}+2 \% \mathrm{Mica}$ as specimen II and $\mathrm{Al} 6063+13 \% \mathrm{SiC}+2 \% \mathrm{Mica}$ as specimen III and $\mathrm{Al} 6063+14 \% \mathrm{SiC}+2 \% \mathrm{Mica}$ as specimen IV.

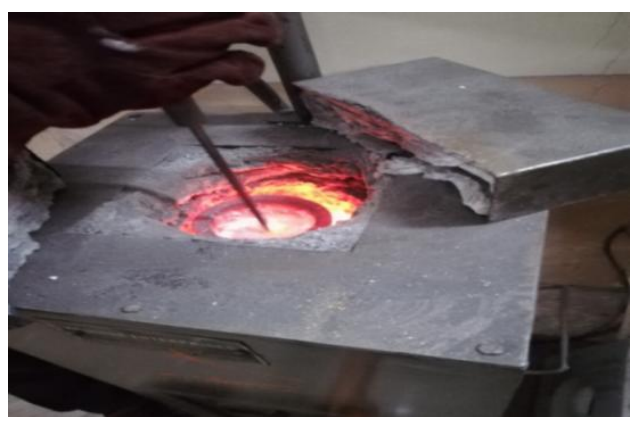

Figure 1 


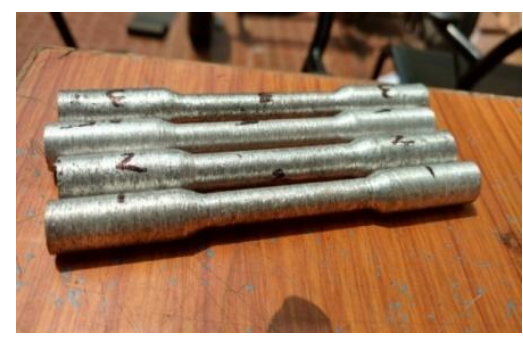

Figure 2

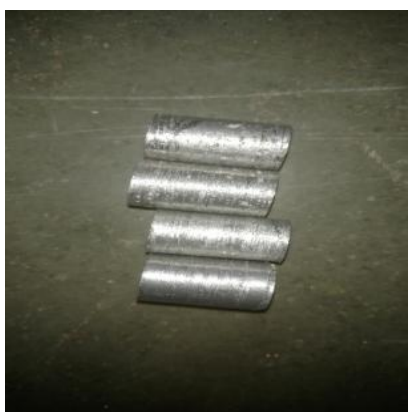

Figure 3

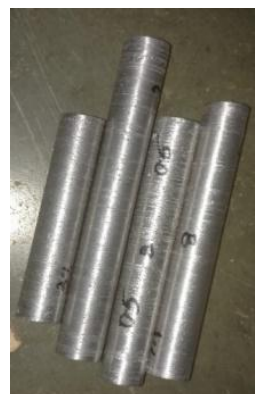

Figure 4

\section{RESULTS AND DISCUSSIONS:}

Microstructures obtained are as shown in the figures 5,6 and 7,8 .

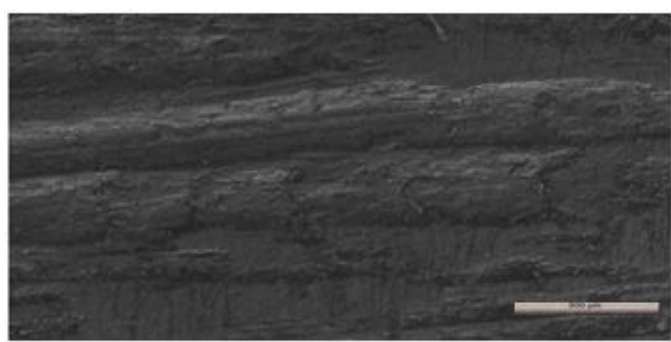

Figure 5, Al6063

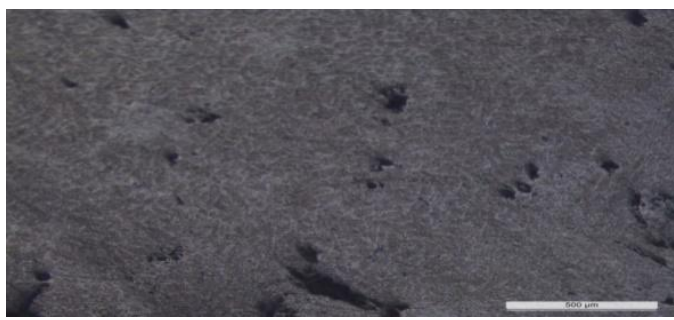

Figure 6, Al6063+12\% SiC+2\% Mica

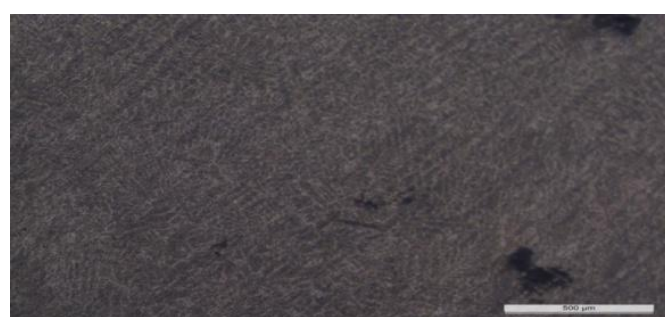

Figure 7, Al6063+13\% Sic+2\% Mica

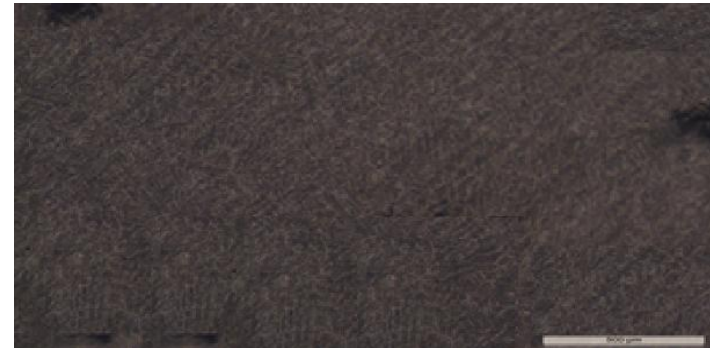

Figure 8, Al6063+14\% Sic+2\%Mica

Clustering of Sic has been elevated as the percentage of $\mathrm{SiC}$ has been increased from $12 \%$ to thirteen $\%$ with Mica final regular. The clustering is attributed to $\mathrm{SiC}^{\prime} \mathrm{s}$ low thermal conductivity and warmth diffusivity. This indicates that $\mathrm{SiC}$ 's are always pushed toward dendritic the the front throughout solidification

\section{MICRO-HARDNESS}

with the aid of the Vickers hardness system be discovered that the hardness is reduced. The Hardness have been reduced compared to perfect Aluminium 6063 alloy as the $\mathrm{SiC}$ content increases. The is finished for the threecomposites one with $12 \%$, thirteen $\%, 14 \%$ ofSiC and Mica is maintained constant at $2 \%$ in each composites

Table 1: Vickers hardness

\begin{tabular}{|l|l|l|}
\hline S.No & \multicolumn{1}{|c|}{ Content } & \multicolumn{1}{|c|}{ Vicker hardness } \\
\hline 1 & Ideal Al6063 (I) & 83 \\
\hline 2 & $\begin{array}{l}\text { Al6063+ 12\% SiC+ 2\% } \\
\text { Mica (II) }\end{array}$ & 35.5 \\
\hline 3 & $\begin{array}{l}\text { Al6063+ 13\% SiC+ 2\% } \\
\text { Mica (III) }\end{array}$ & 35.8 \\
\hline 4 & $\begin{array}{l}\text { Al6063+ 14\% SiC+ 2\% } \\
\text { Mica (IV) }\end{array}$ & 36.3 \\
\hline
\end{tabular}
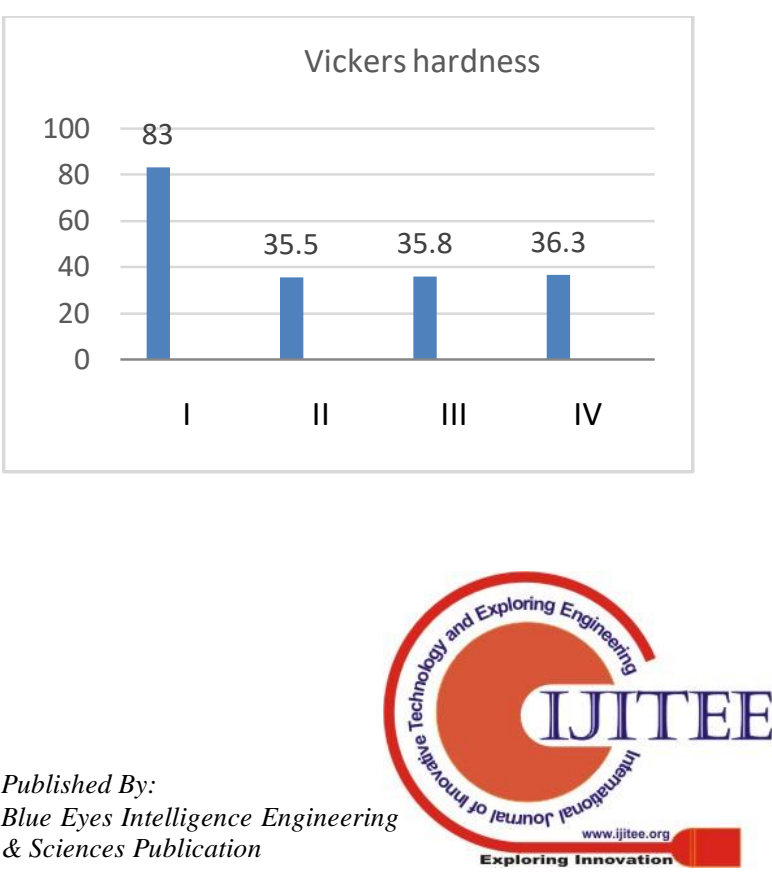


\section{TENSILE STRENGHT TEST:}

Tensile strength has been decreased as compared to ideal Aluminium alloy as $\mathrm{SiC}$ percentage increases from $12 \%$, $13 \%$ and $14 \%$ with Mica remaining constant at $2 \%$.

Table 2: Tensile strength test

\begin{tabular}{|l|l|l|}
\hline S.No & Content & $\begin{array}{l}\text { Ultimate } \\
\text { tensile strength }\end{array}$ \\
\hline 1 & Al6063 (I) & 241 \\
\hline 2 & Al6063+12\%SiC+2\%Mica (II) & 46.51 \\
\hline 3 & Al6063+13\%SiC+2\%Mica (III) & 19.14 \\
\hline 4 & Al6063+14\%SiC+2\%Mica (IV) & 8.27 \\
\hline
\end{tabular}

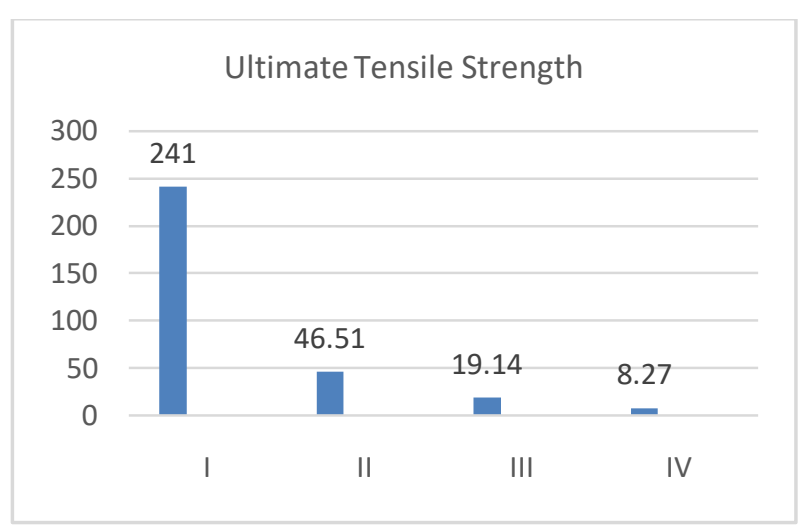

\section{COMPRESSIVE STRENGHT TEST:}

The compressive strength test is conducted in Instron machine and the compressive strength is increased drastically for ideal Al6063 and composite material (Al6063+12\%SiC+2\%Mica).The compressive strength has decreased as $\mathrm{SiC}$ content increased.

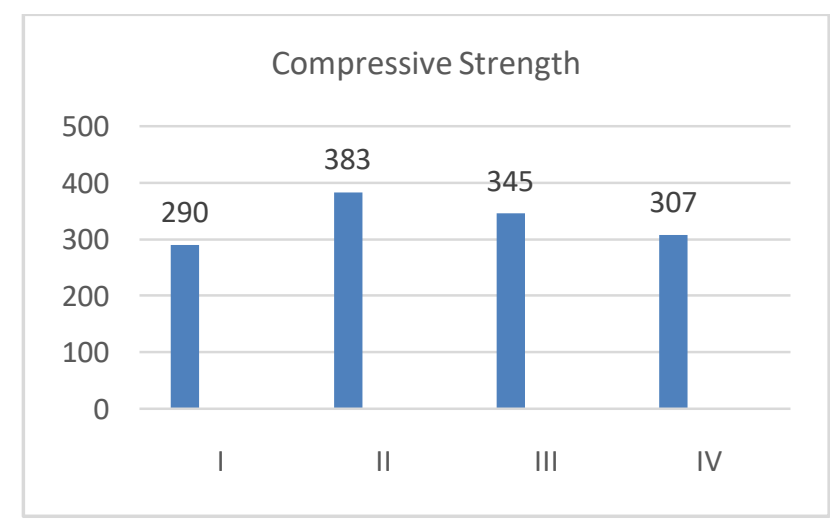

\section{FLUXURAL STRENGTH TEST}

Flexural strength has been decreased as the percentage of $\mathrm{SiC}$ is increased from $12 \%, 13 \%$, and $14 \%$ with Mica remaining constant $(2 \%)$ but when compared relatively.

Table 3: Flexural strength test

\begin{tabular}{|l|l|l|l|}
\hline S.No & Content & $\begin{array}{l}\text { Stress(MP } \\
\text { a) }\end{array}$ & $\begin{array}{l}\text { Maximum } \\
\text { Load(N) }\end{array}$ \\
\hline 1 & Al6063 & 26.7 & 2587.5 \\
\hline 2 & $\begin{array}{l}\text { Al6063+12\%SiC } \\
+2 \% \text { Mica (II) }\end{array}$ & 42.8 & 1832.9 \\
\hline 3 & $\begin{array}{l}\text { Al6063+13\%SiC } \\
+2 \% \text { Mica (III) }\end{array}$ & 59.98 & 1077.77 \\
\hline
\end{tabular}

\section{Stress(MPa)}

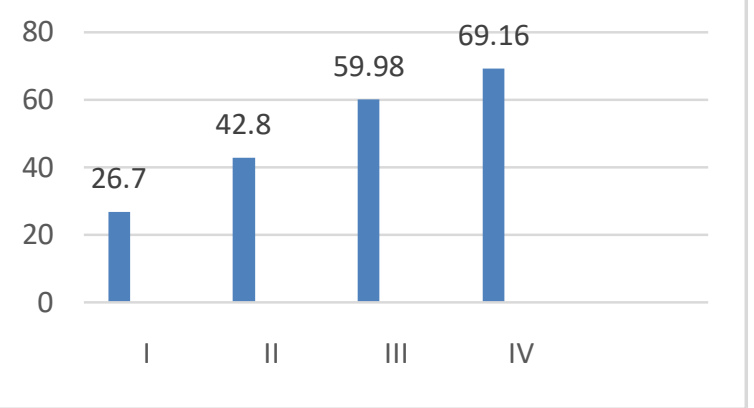

\section{Maximum Load}

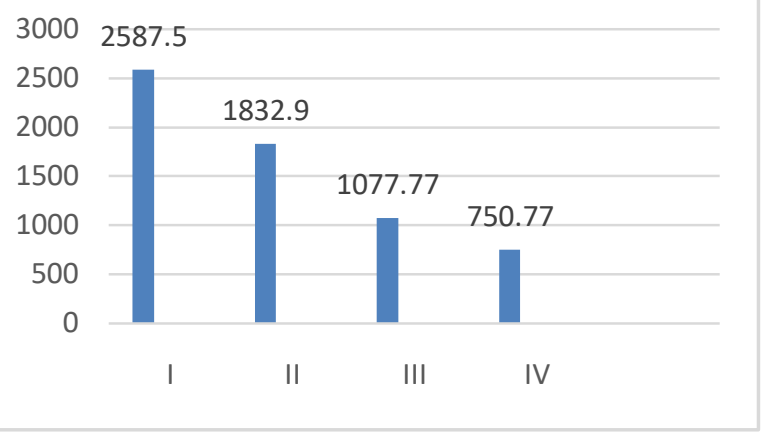

\section{CONCLUSIONS:}

1. The flexibility of composite is reduced through ninety six.56\% with advancement in the silicon carbide percent. So it'd now not be profitable to trademark even more $\mathrm{SiC}$ content material surface.

2. The flexural control ( inMPa) of the composite (IV) is improved by using technique for $259.02 \%$ with impact in the silicon carbide and keeping up mica content material persevering.

3. The compressive imperativeness of composite is connected with the benefit of $32.06 \%$ in precedent II.

4. Micro hardness test demonstrates that the hardness of composite will impact with growing $\mathrm{SiC}$ content material.

5. Clustering of silicon carbide atom is extended inside the composite with growing $\mathrm{SiC}$ content material. The grouping is credited to $\mathrm{SiC}^{\prime}$ s low warm conductivity and warmth diffusivity.

\section{REFERENCES}

1. S.S.Lokesh, group, assessment, assembling and trying out the mechanical homes of chamber the utilization of Aluminum metal cross section composite, worldwide magazine of associated Engineering research, ISSN 0973-4562 Vol. 10 No.sixty eight (2015).

2. incredibleenough.M. Shorowordi, T. Laoui, A.S.M.A. Haseeb, J.P. Celis, L. Froyen, Microstructure and interface qualities of $\mathrm{B} 4 \mathrm{C}, \mathrm{SiC}$ and $\mathrm{Al} 2 \mathrm{O} 3$ invigorated $\mathrm{Al}$ structure

Published By: 
composites: a comparable investigate, J. Mater. structure. Technol. 142 (2003) 738-743.

3. Macke A, Schultz BF, Rohatgi P. steel system composites give the vehicle business a likelihood to lessen vehicle weight, update ordinary execution. Adv Mater frameworks 2012;170(three):19-23.

4. Prabu SB, Karanamoorty L, Kathiresan S, Mohan B. impact of mixing pace and blending time on transport of particulates in cast metal matrix composite. J Mater methodology time 2006; 171:268-seventy three.

5. T.V.Christy, A Comparative examine on the Microstructures and Mechanical spots of $\mathrm{Al} 6061$ Alloy and the MMC Al 6061/TiB2/12P, magazine of Minerals and substances Characterization and Engineering, Vol. nine, No.1, pp.57sixty five, 2010

6. Lancaster L, Lung MH, Sujan D. usage of agro-business waste in steel grid composites: toward viability. world Academy of development, Engineering and time 2013; 73:1136-forty four.

7. R.V.NikhilSantosh, Dr. Shabana, Dr. J. Sarojini, V.V.good enough. Lakshmi, improving the mechanical homes of metal lattice composites by using reinforcing $\mathrm{Al} 6063$ with $\mathrm{SiC}$ and graphite, gave at national show on "current enhancements in Mechanical Engineering" at NIT Rourkela.

8. Prashant $\mathrm{S}$ N,education and examination of mechanical and wear homes of Al6061 reinforced with graphite and $\mathrm{SiC}$ particulate metal system composites, all inclusive journal of Mechanical Engineering and Robotics contemplates, Vol. 1, No. 3, October 2012.

9. T.Rajmohan, extraordinary enough.Palanikumar, and S. Ranganathan. "evaluation of mechanical and wear homes of hybrid aluminum cross section composites." Trans. Nonferrous Met. Soc. China 23.nine (2013): 2509-2517.

10. YanamandalaRaghuramChowdary, evaluation of Mechanical spots of $\mathrm{Al} / \mathrm{SiC}$-Graphite Hybrid steel Matrix Composite, generally magazine of front line tendencies in PC age and Engineering, Vol.2 , No.6, Pages : 286-289 (2013) 